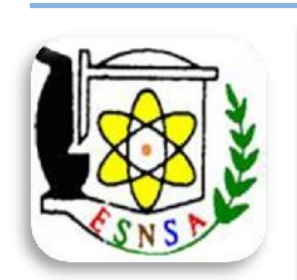

Arab Journal of Nuclear Sciences and Applications

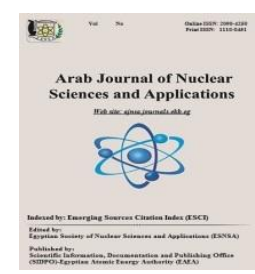

(ESNSA)

\title{
Natural Radioactivity Measurement of Bricks Used in the Building Materials of Egypt
}

\author{
${ }^{1,2}$ S.Fares, ${ }^{3}$ H.A.Yakout \\ ${ }^{I}$ Department of Radiation Physics, National Center for Radiation Research and Technology NCRRT, Atomic Energy \\ Authority, Cairo, Egypt. \\ ${ }^{2}$ Department of Physics, Faculty of Science, Baha University, Saudi Arabia \\ ${ }^{3}$ Department of Physics, Faculty of Science, King Khalid University, Abha, Saudi Arabia
}

Received $13^{\text {th }}$ Dec. 2018 Percentage and radionuclides content in the brick material used in construction depend on the origin Accepted $19^{\text {th }}$ May 2019 and the geological condition of the source material. Bricks used as building materials in Egypt were manufactured from clay and rocks extracted from deposited sediments of Nile River. The aim of the study was to determine the radiation activity resulting from a different kind of bricks used in the construction process in Egypt. In the present work, 20 samples of three types of bricks, clay brick (CB), making facade brick (MFB) and firebrick (FB) were selected from different regions and plants in Egypt. The activity concentration of ${ }^{226} \mathrm{Ra},{ }^{232} \mathrm{Th}$ and ${ }^{40} \mathrm{~K}$ in many brick under investigation were measured using gamma ray spectroscopy system. Results showed that, the radium equivalent concentration (Raeq) calculated and compared well with the world reported values. As shown in the results, the mean values of radioactivity concentrations of ${ }^{226} \mathrm{Ra},{ }^{232} \mathrm{Th}$ and ${ }^{40} \mathrm{~K}$ for $\mathrm{CB}$ bricks, which represent the highest ??? in many bricks in the present study with values $(39,38$ and $199 \mathrm{~Bq} / \mathrm{kg})$, respectively. Radium equivalent activities calculated for many bricks in the study???. The average values of radium equivalent activities 110, 88 and $83 \mathrm{~Bq} / \mathrm{kg}$, for bricks type were found to be below the global level of 370 $\mathrm{Bq} / \mathrm{kg}$ of building materials. The maximum values of $\mathrm{Ra}_{\mathrm{eq}}$ calculated for all studied samples were found to be $152.79 \mathrm{~Bq} / \mathrm{kg}$ for (CB4) sample, 112.0 for (MFB10) sample, and $118.77 \mathrm{~Bq} / \mathrm{kg}$ for (FB20) sample. To test the radiological hazard of the natural radioactivity, the potential radiological hazards were assessed by calculating the indoor absorbed gamma dose rate (DR), the annual effective dose rate, outdoor and indoor (Deff), the alpha index (I $\alpha$ ), the gamma index (I $\gamma$ ), and the external hazard (Hex) and internal hazard (Hin) indices. Considering that the values of the risk indicators were lower than the recommended levels, we have concluded that the buildings constructed from these brick samples in our study are safe for the population.

Keywords: Brick, Radioactivity, Health hazard indices, Radium equivalent, HPGe.

\section{Introduction}

Radiation background is one of the active environmental factors that are very significant in a human's life. It is important to show population exposures in buildings resulting from natural radioactivity in building materials, which a source of exposure to indoor radiation. The appoint of ${ }^{226} \mathrm{Ra},{ }^{232} \mathrm{Th}$ and ${ }^{40} \mathrm{~K}$ content in building materials is the main concern indoor radiation in dwellings which produces significant internal and external dose rates in $\mathrm{nGy} / \mathrm{h}[1,2]$. So, the activity concentration of these radionuclides measured by researchers in various building materials in different countries of the world such as in Egypt [3-8], for different fabricated types of bricks (clay,

Corresponding author: sfares2@yahoo.com

DOI: 10.21608/ajnsa.2019.6648.1153

(C) Scientific Information, Documentation and Publishing Office (SIDPO)-EAEA 
cement, and sand) and used in buildings in Cairo region in Egypt [9].

Due to increased global demand for clay and its industrial importance, clay deposits from rivers are widely used as raw materials for the manufacture of bricks used in construction. In Egypt, bricks are used either brick made of clay or raw brick in construction, which is the largest component in building materials used. Firebrick (FB) and facade brick (MFB) also used in facades and interiors of buildings. Thus, it is important to determine whether the clay bricks release pollutants into the environment and/or as a source of radiation exposure to people when being used as building materials [10]. There is insufficient data about the natural radioactivity of the bricks, which was manufactured from the Nile River clay, which represents the main components of public and residential buildings in Egypt. Therefore, our results can be considered a reference data for the different types of Egyptian clay bricks. The present work aimed to testing the activity concentration of three used bricks materials in Egypt; clay brick (CB), facade brick (MFB) and firebrick (FB), which was the Nile River clay is the raw material used in its manufacture, to estimate the radiological problems associated with their use in constructing houses in Egypt.

\section{Material and Methods}

Sample Description and Preparation

Twenty samples of three common bricks used in Egypt, clay brick (CB), facade brick (MFB) and firebrick (FB) which fabricated using raw materials from the Nile River clay Figs 1, 2, 3, collected from a supplier and building sites from different places in upper Egypt Fig 4. To remove the wetness, the samples placed for 24 hours in oven at $100^{\circ} \mathrm{C}$, the samples then grinded to get a homogeneous powder. Then 20 samples provided seven samples (CB), six samples (MFB) and seven samples (FB). The samples homogenized and then neatly sealed and stored for at least 28 days before analysis with the gamma ray spectrometer to reach secular equilibrium between 226Ra and its decay products.

\section{Experimental Technique}

250 gram of each sample was put in front of the (HPGe) detector system with a relative efficiency of $40 \%$ and an energy resolution of $1.67 \mathrm{keV}$
FWHM at the $1332.5 \mathrm{KeV}$ peak of ${ }^{60} \mathrm{Co}$ shielded by a lead cylinder.

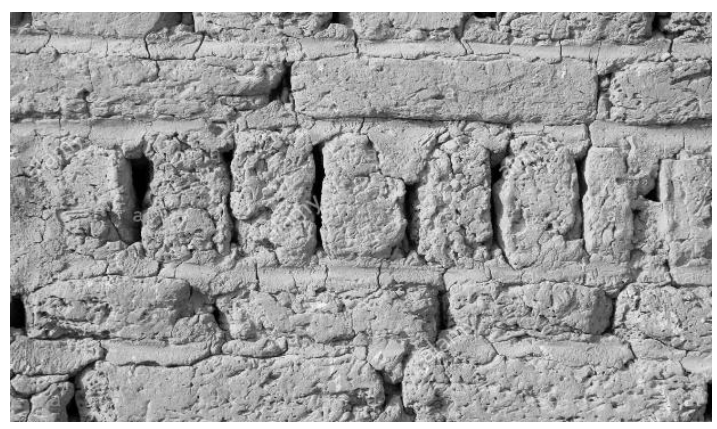

Fig. (1): Clay Brick (CB)

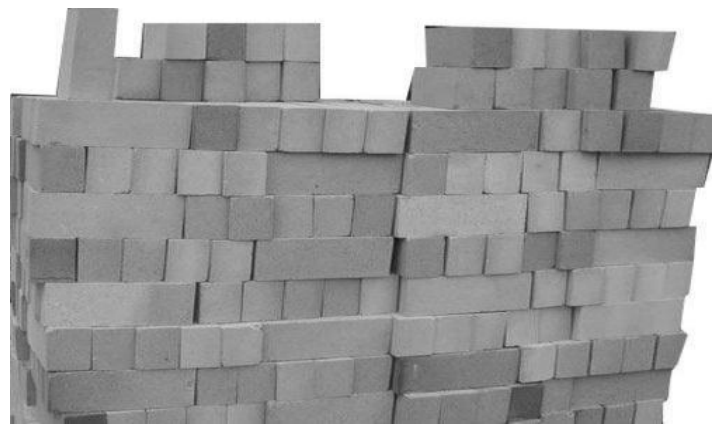

Fig. (2): Fire Brick (FB)

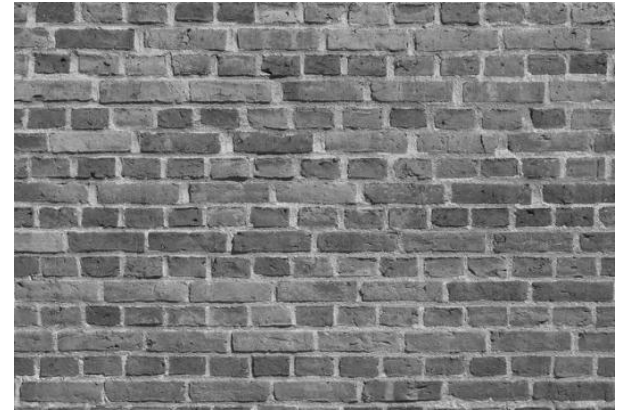

Fig. (3): Facade Brick (MFB)

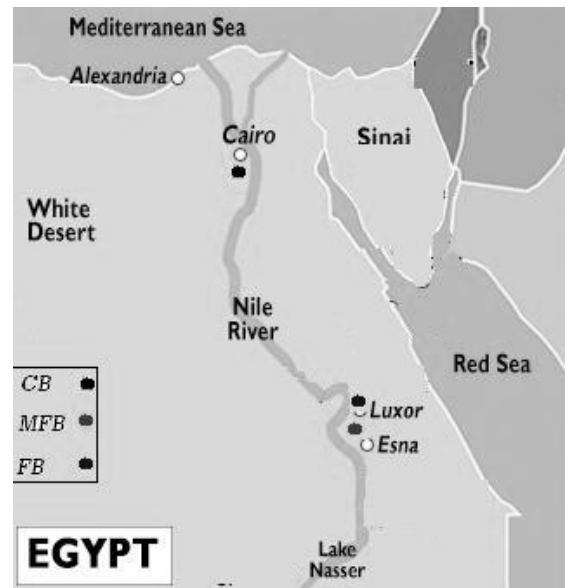

Fig. (4): Site map of CB, MFB and FB brick samples from 
The activity concentration of the natural radioactivity ${ }^{226} \mathrm{Ra},{ }^{232} \mathrm{Th}$ and ${ }^{40} \mathrm{~K}$ in the brick samples measured using the gamma ray spectrometer. One of the most effective systems for measuring and assigning radiation activity is a gamma-ray spectrometer, which we used in this study and with a high-purity germanium detector. In the first, the spectrometer calibrated with ${ }^{137} \mathrm{Cs}$ source. To decide the activity concentration of ${ }^{232} \mathrm{Th}$, the gamma ray line ${ }^{228} \mathrm{Ac}$ $(338,911,970,974.8 \mathrm{KeV})$ and ${ }^{208} \mathrm{Tl}(583.2 \mathrm{KeV})$ used, to decide the activity concentration of ${ }^{226} \mathrm{Ra}$ from uranium series lines $\gamma$-ray ${ }^{214} \mathrm{~Pb}(352 \mathrm{KeV})$ and ${ }^{214} \mathrm{Bi}(609,768.4,1120,1238,1764.5 \mathrm{KeV})$ and to decide ${ }^{40} \mathrm{~K}$ isotope activity $(1461 \mathrm{KeV})$ measured. As mentioned in studies such as [11], the activity concentrations in samples can get using Eq. (1).

$$
A=\frac{N \times 1000}{\varepsilon_{\gamma} \times P_{\gamma} \times T_{s} \times M_{s}}
$$

where $\mathrm{A}$ is the specific activity in $\mathrm{Bq} / \mathrm{kg}, N$ is the net number of counts in the resulting photopeak, $\rho_{\gamma}$ is the intensity at the corresponding gamma-ray energy, $\varepsilon_{\gamma}$ is the efficiency of the HPGe detector at the corresponding gamma-ray energy, $M_{s}$ is the weight of the sample in grams and $\mathrm{T}_{\mathrm{s}}$ is the sample counting time in seconds. For the accuracy of the radiometric measurements, the minimum concentration of detectable radiation activity (MDAC) calculated for the gamma ray spectrometry system using Eq. (2) [12]:

$$
M D A C=\frac{K_{\alpha} \times \sqrt{B}}{\varepsilon_{\gamma} \times P_{\gamma} \times T_{s} \times M_{s}}
$$

Where the statistical coverage factor $\mathrm{K}_{\alpha}$ is equal to 1.86 (at the $95 \%$ confidence level), $\mathrm{B}$ is the number of background counts in the region of interest for a certain radionuclide, $\rho_{\gamma}$ is the gammaray emission probability. $\varepsilon_{\gamma}$ is the efficiency of the HPGe detector at the corresponding gamma-ray energy. $M_{s}$ is the dry weight of the sample $(\mathrm{kg})$ and $\mathrm{T}_{\mathrm{s}}$ is the counting time. In addition, the minimum values of the detectable activity of radionuclides (MDACs) for the gamma-ray detection system of ${ }^{137} \mathrm{Cs},{ }^{232} \mathrm{Th},{ }^{226} \mathrm{Ra}$ and ${ }^{40} \mathrm{~K}$ calculated in values 2 , 3,4 and $25 \mathrm{~Bq} / \mathrm{kg}$ respectively.

\section{Estimation of radiation hazards: \\ Radium equivalent activity}

Radium equivalent activity $\left(\mathrm{Ra}_{\mathrm{eq}}\right)$ is a radiological index of the real activity level of ${ }^{226} \mathrm{Ra},{ }^{232} \mathrm{Th}$ and ${ }^{40} \mathrm{~K}$ in all bricks type. The radium equivalent activity $\left(\mathrm{Ra}_{\mathrm{eq}}\right)$ indicator scale used to determine the actual activity level of the ${ }^{226} \mathrm{Ra},{ }^{232} \mathrm{Th}$ and ${ }^{40} \mathrm{~K}$ elements in the present samples and to estimate the radiation risks associated with these radionuclides. The maximum value for $\mathrm{Ra}_{\mathrm{eq}}$ is equivalent $370 \mathrm{~Bq} / \mathrm{kg}$ equal to $1 \mathrm{mSv} / \mathrm{y}$. The distribution of ${ }^{238} \mathrm{U},{ }^{232} \mathrm{Th}$ and ${ }^{40} \mathrm{~K}$ in samples are not uniform and $\mathrm{Ra}_{\mathrm{eq}}$ can calculate using Eq.3 [13]:

$$
R a_{e q}=1.43 A_{T h}+0.077 A_{K}+A_{R a}
$$

Where $\mathrm{A}_{R a}, \mathrm{~A}_{T h}$ and $\mathrm{A}_{k}(\mathrm{~Bq} / \mathrm{kg})$ are the $\left({ }^{226} \mathrm{Ra}\right.$, ${ }^{232} \mathrm{Th}$ and $\left.{ }^{40} \mathrm{~K}\right)$ activity concentrations $[1,15]$.

\section{Criteria formula $(C F)$}

The annual external radiation dose inside dwellings constructed of building materials, with $\mathrm{Ra}_{\mathrm{eq}}$ value of $370 \mathrm{~Bq} / \mathrm{kg}$ according to the models tested [16-18], and the correction of their assumptions after taking into consideration a wall of finite thickness due to the window and doors and applying a weighing of 0.7 [19]. To reduce the annual radiation dose generated from building materials, the Criteria formula (CF) computed based on the Eq. 4

$$
\frac{A_{R a}}{740}+\frac{A_{T h}}{520}+\frac{A_{K}}{9620}<1
$$

\section{Dose rate measurement}

The external absorbed dose rate $D_{R}$ due to the uniform distribution of the radionuclides under investigation at $1 \mathrm{~m}$ above of ground surface for ${ }^{238} \mathrm{U},{ }^{232} \mathrm{Th}$ and ${ }^{40} \mathrm{~K}$ radioisotope used in Eq.5:

$$
D_{R}=\left(0.461 A_{R}+0.604 A_{T h}+0.0417 A_{k}\right) n G y / h
$$

Where $D_{R}$ the gamma dose rate is in the outdoor air at $1 \mathrm{~m}$ over the ground and $A_{R a}, A_{T h}$ and $A_{K}$ are

Arab J. Nucl. Sci. \& Applic. Vol. 52, No. 4 (2019) 
the activity concentrations $\mathrm{Bq} / \mathrm{kg}$ of ${ }^{238} \mathrm{U},{ }^{232} \mathrm{Th}$ and ${ }^{40} \mathrm{~K}$ radium, and $\mathrm{D}_{\mathrm{R}}$ in $(\mathrm{nGy} / \mathrm{h})$ [13]. The annual effective dose rate $\left(D_{\text {eff }}\right)$ comprises three factors. The conversion factor $(\mathrm{CF})$ that converts the absorbed dose in air to the corresponding effective dose $(\mathrm{CF}=0.7)$, then the outdoor occupancy factor (OF), while people spend $(80 \%)$ of their time in buildings $(\mathrm{OF}=0.8)$, and people spending abroad of their time outside buildings is $(\mathrm{OF}=0.2)$. Finally, the ratio of gamma dose rates indoor to outdoor $(\mathrm{R}=1.4)$. Annual effective dose rate $(\mathrm{Sv} / \mathrm{y})$ using Eq. 6:

$$
D_{\text {eff }}=D \times C F \times O F \times R \times 8760
$$

Where: $\mathrm{D}$ is the dose rate in $(\mathrm{Gy} / \mathrm{h})$ and 8760 is hours in year $[13,20]$

\section{Hazard indexes for gamma and alpha radiation}

European Commission [21] confesses an index that named (I $\gamma$ ) gamma index, defined for use as a screening tool for categorizing materials used in construction. Gamma index used to verify whether the guidelines of EC for constructing material sage met. Gamma index estimated using Eq.7:

$$
I_{\gamma}=\frac{A_{R a}}{150}+\frac{A_{T h}}{100}+\frac{A_{K}}{1500}
$$

Where: $A_{T h}, A_{R a}$ and $A_{K}$ are the activity concentration of ${ }^{232} \mathrm{Th},{ }^{226} \mathrm{Ra}$ and ${ }^{49} \mathrm{~K}$ in $\mathrm{Bq} / \mathrm{kg}[13$, 20]. Alpha index suggested for estimation alpha radiation that is emitted radon gas at constructing materials. I $\alpha$ and $\mathrm{I} \gamma$ is below 0.5 and 1. Alpha index calculated from Eq. 8: [14, 22].

$$
I_{\alpha}=\frac{A_{R a}}{200}
$$

$A_{R a} \mathrm{~Bq} / \mathrm{kg}$ is the activity concentration of ${ }^{226} \mathrm{Ra}$ assumed in equilibrium with ${ }^{238} \mathrm{U}$. The activity concentrations recommended exemption and upper level of ${ }^{226} \mathrm{Ra}$ in soil are 100 and $200 \mathrm{~Bq} / \mathrm{kg}$. The recommended upper limit concentration of ${ }^{226} \mathrm{Ra}$ is $200 \mathrm{~Bq} / \mathrm{kg}$, for which $I \alpha=1$.

\section{Internal hazard and external hazard indexes}

${ }^{222} \mathrm{Rn}$ plays an important role in internal exposure in the room and the gamma ray effect. Internal hazard index $\mathrm{H}_{\text {in }}$ used to decide the internal exposure due to radon ${ }^{222} \mathrm{Rn}$ and its daughter in the building material. Indices values must be $<1$. $\mathrm{H}_{\text {in }}$ and calculated from Eq.9: [23].
$H_{\text {in }}=\frac{A_{R a}}{185}+\frac{A_{T h}}{259}+\frac{A_{K}}{4810} \leq 1$

External gamma radiation $\left(\mathrm{H}_{\mathrm{ex}}\right)$ does product by construction material radionuclides such as clay brick, while the upper limit of radiation dose arising from building materials is $1.5 \mathrm{mSv} / \mathrm{y}$.

To calculate the specific external hazard index the conservative model which designed to be thick, boundless walls and without windows or doors, should consider. This model considered as a standard for calculating the external risk index and as defined from the equation as Eq. 10: [18].

$$
H_{e x}=\frac{A_{R a}}{370}+\frac{A_{T h}}{259}+\frac{A_{K}}{4810} \leq 1
$$

It is proper to emphasize that a correlation in considering the criterion of this model that the $\mathrm{H}_{\mathrm{ex}}$ axis due to gamma radiation corresponds to the maximum of $\mathrm{Ra}_{\mathrm{eq}}$ of $370 \mathrm{~Bq} / \mathrm{kg}$ for all materials.

\section{Results and Discussion}

In this study, the activity concentration for ${ }^{226} \mathrm{Ra},{ }^{232} \mathrm{Th}$ and ${ }^{40} \mathrm{~K}$ measured from different types of bricks used in Egypt. The results measured in Table 1 presented to show the distribution of natural radionuclides in basic building materials such as clay bricks used in construction in Egypt. We found that the radioactivity value varies from the brick type to another. The activity concentration of ${ }^{226} \mathrm{R}$ differs (from 33 to 46 ) Bq/kg, with a mean of $39 \mathrm{~Bq} / \mathrm{kg}$. Table 1 also has the maximum and minimum values with mean values of the activity concentration measured for the brick (CB). The activity concentration of ${ }^{232} \mathrm{Th}$ varies (from 31 to 61) $\mathrm{Bq} / \mathrm{kg}$ and the arithmetic mean is $38 \mathrm{~Bq} / \mathrm{kg}$. The activity concentration of ${ }^{40} \mathrm{~K}$ varies (from 137 to 293$) \mathrm{Bq} / \mathrm{kg}$ and the arithmetic mean is 199 $\mathrm{Bq} / \mathrm{kg}$. The mean values of ${ }^{226} \mathrm{Ra}$ and ${ }^{232} \mathrm{Th}$ are greater than worldwide average values ( 35 and $30 \mathrm{~Bq} / \mathrm{kg}$ ) respectively, while the mean value of ${ }^{40} \mathrm{~K}$ are lower than the corresponding worldwide average values which $400 \mathrm{~Bq} / \mathrm{kg}$ while based on the guidelines provided by [10]. Table 1 shows that for (MFB) brick, the activity concentration had the same characteristics as the (CB) brick. So that, the mean values of ${ }^{226} \mathrm{Ra}$ and ${ }^{232} \mathrm{Th}$ are greater than worldwide average values ( 35 and $30 \mathrm{~Bq} / \mathrm{kg}$ ) for ${ }^{226} \mathrm{Ra}$ and ${ }^{232} \mathrm{Th}$ respectively, while the mean 
value of ${ }^{40} \mathrm{~K}$ are lower than the corresponding worldwide average values which $400 \mathrm{~Bq} / \mathrm{kg}$. While there was a significant variation in the (FB) brick, the mean values of ${ }^{226} \mathrm{Ra}$ and ${ }^{232} \mathrm{Th}$ and ${ }^{40} \mathrm{~K}(33,22$ and $221 \mathrm{~Bq} / \mathrm{kg}$ ) were significantly lower than the global averages $(35,30$ and $400 \mathrm{~Bq} / \mathrm{kg})$. In general, our results, which measure the activity concentration of ${ }^{226} \mathrm{Ra}$ and ${ }^{232} \mathrm{Th}$ and ${ }^{40} \mathrm{~K}$ in all study samples, were found to be within the limits of the Alharbi ${ }^{24}$. The study average activity concentration of ${ }^{226} \mathrm{Ra},{ }^{232} \mathrm{Th}$, and ${ }^{40} \mathrm{~K}$, in clay samples was (36, 28 and 208) $\mathrm{Bq} / \mathrm{kg}$, which resulted from the use of clay as raw materials in construction in Egypt.

In terms of Radium equivalent activity (Raeq), we found that the values for all types of bricks measured in the present work were lower than the reference values of the upper limit unity for $\mathrm{Ra}_{\mathrm{eq}}$ is equivalent to $370 \mathrm{~Bq} / \mathrm{kg}$ corresponds to $1 \mathrm{mSv} / \mathrm{y}$. The calculated values of the radium equivalent $\mathrm{Ra}_{\mathrm{eq}}$ for all types of studied bricks are (110, 88 and 83) $\mathrm{Bq} / \mathrm{kg}$ for (CB), (MFB) and (FB) bricks, respectively, these values were higher than $R_{\text {eq }}$ value $(78.2 \mathrm{~Bq} / \mathrm{kg})$ in El-Tahawy et.al. ${ }^{9}$ study for clay brick. This quantity does not pose a radiological hazard and provides a useful guideline in regulating the safety standards in radiation protection for a human population. The bricks used in Egypt are so safe to use.

The Criteria formula (CF) to limit the annual radiation dose from building materials based on the formula Eq. 4. Table 2, the values of the Criteria formula (CF) for the brick samples in the present study ranged (from 0.11 to 0.21 ) for (CB) brick, (from 0.09 to 0.15 ) for (MFB) brick and (from 0.08 to 0.16 ) for (FB) brick. The average values $(0.15,0.12$ and 0.11$)$ for all types of studied brick samples respectively are less than the recommended value $(<1)$. Therefore, the brick used safe because the level of radiation activity does not exceed the limits allowed in the world in building materials.

Due to the activity concentrations of ${ }^{238} \mathrm{U},{ }^{232} \mathrm{Th}$ and ${ }^{40} \mathrm{~K}$, the gamma absorbed dose rates in air gamma at $1 \mathrm{~m}$ above ground level calculated in Table 2. The mean value of absorbed dose rates of clay brick (CB), making the facade brick (MFB) and fire brick (FB) are of (50.01, 40.80 and 38.47) $\mathrm{nGy} / \mathrm{h}$. After calculating the gamma absorption, dose rate values the estimated mean value of $D_{R}$ in the studied samples found to be slightly below the corresponding value in the Ahmed et.al. ${ }^{3}$ study
$(60.3 \pm 8 \mathrm{nGy} / \mathrm{h})$. Global average of indoor absorbed gamma dose rate at $84 \mathrm{nGy} / \mathrm{h}$ [10]. The outdoor annual effective dose rate $\left(D_{\text {eff }}\right)$ mean value of clay brick (CB), making the facade brick (MFB) and fire brick (FB) are of (0.06, 0.05 and $0.05) \mathrm{mSv} / \mathrm{y}$. The indoor annual effective dose rate $\left(D_{\text {eff }}\right.$ mean values of clay brick $(\mathrm{CB})$, making the facade brick (MFB) and fire brick (FB) are of $(0.25,0.20$ and 0.19$) \mathrm{mSv} / \mathrm{y}$ in Table 2. The absorbed dose rate $D_{R}$, and annual effective dose $D_{\text {eff }}$ in clay bricks samples in [6] study were found as follows $(0.28$ to $0.7 \mathrm{nGy} / \mathrm{h}$ and 1.3 to $3.5 \mu \mathrm{sv})$. These values are lower than the corresponding values of all the clay bricks used in our study. This result may be due to the fact that the Radium equivalent activity Raeq and ${ }^{226} \mathrm{Ra}$ activity concentration in this study were (77.8 to 201.6 and $16 \pm 1$ to $52 \pm 3$ ) in contrast to the same values in our study which were $(110,88,83$ and $39,33,33)$ for all clay bricks type.

The index I $\gamma$ correlated with the annual dose due to the excess external gamma radiation caused by superficial material. Values of index $\mathrm{I} \gamma \leq 1$ correspond to $0.3 \mathrm{mSv} / \mathrm{y}$, while $\mathrm{I} \gamma \leq 3$ correspond to $1 \mathrm{mSv} / \mathrm{y}$. Thus, the activity concentration index should use only as a screening tool for identifying materials which might of a concern to used as the covering material European Commission $(\mathrm{EC})^{21}$.Calculated values of gamma index for all types of clay bricks analyzed in this work tabulated in Table2. Values of I $\gamma$ detected for brick samples studied and the mean values are $(0.78,0.64$ and 0.60 ) for CB, MFB and FB bricks got. Since I $\gamma$ index for many bricks does not exceed the upper limit for the representative level which unity, except the (CB4) brick samples, which have values of 1.09 , so it should be no radiological significance for the most samples. The alpha-index values $(I \alpha)$ that tested much lower than the world average $(<$ 1) of internal exposure. We have confirmed that indoor radon concentrations did not exceed the recommended activity level of $200 \mathrm{~Bq} / \mathrm{m}^{3}$ from the results got in Table 1, showing that the concentrations of ${ }^{226} \mathrm{Ra}$ activity concentrations in the study samples were well below $200 \mathrm{~Bq} / \mathrm{kg}$. As Table 2 shows alpha and gamma indexes have the maximum value 1.09 for (CB4) and 0.23 for (CB3) for I $\gamma$ and I $\alpha$ respectively, that are I $\alpha$ below the recommended level 1 ,while I $\gamma$ higher than unity . According to the calculations done in Table 2, In general, $\mathrm{H}_{\mathrm{in}}$ and $\mathrm{H}_{\mathrm{ex}}$ risk indicators of the various clay brick samples studied are lower than the unit. 
These results correspond exactly to the studies of both $[5,6]$ for Clay bricks. This measurement and calculations showed that all clay bricks in Egypt building are safely. According to [10], we found that the annual effective dose for all these samples under study did not exceed the global exposure average of $1.5 \mathrm{mSv} / \mathrm{y}$ as a result of natural sources such as bricks.

The estimated values of the external and internal hazard indices Table 2 for all types of clay brick samples analyzed in the present work found to be less than the recommended limit of 1 for the safe use of a material in the construction of dwellings [10]. The calculated values of $\mathrm{H}_{\mathrm{ex}}$ ranged from 0.22 (CB1) to 0.41 (CB4), with an average of 0.30 for (CB) bricks, from 0.19 (MFB11) to 0.30 (MFB10), with an average of 0.24 for (MFB) bricks and from 0.16 (FB19) to 0.32 (FB20), with an average of 0.22 for (FB) bricks. We found that the mean value of $\mathrm{H}_{\mathrm{in}}$ and $\mathrm{H}_{\mathrm{ex}}$ are $(0.34$ and 0.24$)$ in the [5] study, which is a very close result to our results in all types of bricks used in the present study. As shown in Table 2, the calculated mean values of $\mathrm{H}_{\text {in }}$ got for the different brick samples examined in present study are all lower than the exemption levels and far lower than the upper limit, which implies that all the clay brick materials can use with no restrictions. This measurement and calculations showed that all the bricks used in Egypt building are safely.

Table (1): Activity concentrations of ${ }^{226} \mathrm{Ra},{ }^{232} \mathrm{Th}$ and ${ }^{40} \mathrm{~K}$, Radium Equivalent $\left(\mathrm{Ra}_{\mathrm{eq}}\right)$ and Criteria formula $(\mathrm{CF})$ for all type bricks sample.

\begin{tabular}{cccccc}
\hline Sample No. & ${ }^{226}$ Ra & ${ }^{232} \mathbf{T h}$ & ${ }^{40} \mathbf{K}$ & $\mathbf{R a}_{\text {eq }}$ & CF \\
\hline CB1 & $38 \pm 3.1$ & $27 \pm 1.6$ & $51 \pm 4.6$ & 80.54 & 0.11 \\
CB 2 & $44 \pm 2.5$ & $34 \pm 1.5$ & $234 \pm 11.3$ & 110.64 & 0.15 \\
CB 3 & $46 \pm 3.2$ & $39 \pm 2.1$ & $262 \pm 13.5$ & 121.94 & 0.16 \\
CB 4 & $43 \pm 3.3$ & $61 \pm 3.3$ & $293 \pm 14.1$ & 152.79 & 0.21 \\
CB 5 & $33 \pm 2.4$ & $46 \pm 3.2$ & $137 \pm 9.2$ & 109.33 & 0.15 \\
CB 6 & $40 \pm 2.1$ & $33 \pm 1.8$ & $146 \pm 9.6$ & 98.43 & 0.13 \\
CB 7 & $34 \pm 1.5$ & $31 \pm 1.1$ & $273 \pm 12.1$ & 99.35 & 0.13 \\
\hline Mean+SD & $\mathbf{3 9}$ & $\mathbf{3 8}$ & $\mathbf{1 9 9}$ & $\mathbf{1 1 0}$ & $\mathbf{0 . 1 5}$ \\
Max & $\mathbf{4 6}$ & $\mathbf{6 1}$ & $\mathbf{2 9 3}$ & $\mathbf{1 5 2}$ & $\mathbf{0 . 2 1}$ \\
Min & $\mathbf{3 3}$ & $\mathbf{3 1}$ & $\mathbf{1 3 7}$ & $\mathbf{9 8}$ & $\mathbf{0 . 1 1}$ \\
MFB 8 & $33 \pm 1.5$ & $22 \pm 0.9$ & $283 \pm 13.2$ & 86.25 & 0.12 \\
MFB 9 & $41 \pm 2.5$ & $22 \pm 1.8$ & $131 \pm 5.4$ & 82.55 & 0.11 \\
MFB 10 & $31 \pm 1.8$ & $49 \pm 2.6$ & $142 \pm 6.9$ & 112.00 & 0.15 \\
MFB 11 & $26 \pm 1.4$ & $18 \pm 0.9$ & $235 \pm 11.3$ & 69.84 & 0.09 \\
MFB 12 & $37 \pm 2.3$ & $21 \pm 1.2$ & $252 \pm 12.5$ & 86.43 & 0.12 \\
MFB 13 & $34 \pm 1.6$ & $29 \pm 1.4$ & $263 \pm 11.5$ & 95.72 & 0.13 \\
\hline Mean+SD & $\mathbf{3 3}$ & $\mathbf{2 6}$ & $\mathbf{2 1 7}$ & $\mathbf{8 8}$ & $\mathbf{0 . 1 2}$ \\
Max & $\mathbf{4 1}$ & $\mathbf{4 9}$ & $\mathbf{2 8 3}$ & $\mathbf{1 1 2}$ & $\mathbf{0 . 1 5}$ \\
Min & $\mathbf{2 6}$ & $\mathbf{1 8}$ & $\mathbf{1 3 1}$ & $\mathbf{6 9}$ & $\mathbf{0 . 0 9}$ \\
\hline FB14 & $42 \pm 3.5$ & $20 \pm 2.3$ & $274 \pm 15.6$ & 91.70 & 0.12 \\
FB15 & $28 \pm 2.4$ & $30 \pm 2.3$ & $217 \pm 11.6$ & 87.61 & 0.12 \\
FB16 & $35 \pm 1.9$ & $14 \pm 0.6$ & $253 \pm 12.5$ & 74.50 & 0.10 \\
FB17 & $38 \pm 1.9$ & $11 \pm 0.4$ & $183 \pm 9.6$ & 67.82 & 0.09 \\
FB18 & $32 \pm 2.7$ & $23 \pm 2.1$ & $225 \pm 12.5$ & 82.22 & 0.11 \\
FB19 & $24 \pm 1.9$ & $18 \pm 1.2$ & $128 \pm 5.6$ & 59.60 & 0.08 \\
FB20 & $38 \pm 2.3$ & $42 \pm 2.8$ & $269 \pm 13.1$ & 118.77 & 0.16 \\
\hline Mean+SD & $\mathbf{3 3}$ & $\mathbf{2 2}$ & $\mathbf{2 2 1}$ & $\mathbf{8 3}$ & $\mathbf{0 . 1 1}$ \\
Max & $\mathbf{4 2}$ & $\mathbf{4 2 . 0 0}$ & $\mathbf{2 7 4}$ & $\mathbf{1 1 8}$ & $\mathbf{0 . 1 6}$ \\
Min & $\mathbf{2 4}$ & $\mathbf{1 1}$ & $\mathbf{1 2 8}$ & $\mathbf{5 9}$ & $\mathbf{0 . 0 8}$ \\
Global & $\mathbf{3 5}$ & $\mathbf{3 0}$ & $\mathbf{4 0 0}$ & $\mathbf{3 7 0}$ & $<\mathbf{1}$ \\
Average* & & & & & \\
\hline & & & & & \\
\hline
\end{tabular}

- Global Average*: Ref, [10] 
Table (2): Values of Dose rate measurement, Hazard indexes for gamma and alpha radiation, radiation hazard parameters and internal hazard and external hazard indexes for all type bricks sample

\begin{tabular}{|c|c|c|c|c|c|c|c|}
\hline $\begin{array}{c}\text { Sample } \\
\text { No. }\end{array}$ & $D(n G y / h)$ & $\begin{array}{c}\text { Deff } \\
\text { outdoor } \\
(\mathrm{mSv} / \mathrm{y})\end{array}$ & $\begin{array}{c}\text { Deff } \\
\text { indoor } \\
(\mathrm{mSv} / \mathrm{y})\end{array}$ & $I_{\text {gamma }}$ & $I_{\text {alpha }}$ & $\mathbf{H}_{\mathrm{ex}}$ & $H_{\text {in }}$ \\
\hline CB1 & 36.45 & 0.04 & 0.18 & 0.56 & 0.19 & 0.22 & 0.32 \\
\hline CB 2 & 51.20 & 0.06 & 0.25 & 0.79 & 0.22 & 0.30 & 0.42 \\
\hline CB 3 & 56.40 & 0.07 & 0.27 & 0.87 & 0.23 & 0.33 & 0.45 \\
\hline CB 4 & 69.97 & 0.08 & 0.34 & 1.09 & 0.22 & 0.41 & 0.53 \\
\hline CB 5 & 49.52 & 0.06 & 0.24 & 0.77 & 0.17 & 0.30 & 0.38 \\
\hline CB 6 & 45.06 & 0.05 & 0.22 & 0.69 & 0.20 & 0.27 & 0.37 \\
\hline CB 7 & 46.34 & 0.06 & 0.22 & 0.72 & 0.17 & 0.27 & 0.36 \\
\hline Mean & 50.01 & 0.06 & 0.25 & 0.78 & 0.20 & 0.30 & 0.41 \\
\hline Max & 68.89 & 0.08 & 0.34 & 1.09 & 0.23 & 0.41 & 0.53 \\
\hline Min & 35.95 & 0.04 & 0.18 & 0.56 & 0.17 & 0.22 & 0.32 \\
\hline MFB 8 & 40.71 & 0.05 & 0.20 & 0.63 & 0.17 & 0.23 & 0.32 \\
\hline MFB 9 & 38.07 & 0.05 & 0.18 & 0.58 & 0.21 & 0.22 & 0.33 \\
\hline MFB 10 & 50.67 & 0.06 & 0.24 & 0.79 & 0.16 & 0.30 & 0.39 \\
\hline MFB 11 & 32.99 & 0.04 & 0.16 & 0.51 & 0.13 & 0.19 & 0.26 \\
\hline MFB 12 & 40.64 & 0.05 & 0.20 & 0.62 & 0.19 & 0.23 & 0.33 \\
\hline MFB 13 & 44.68 & 0.05 & 0.22 & 0.69 & 0.17 & 0.26 & 0.35 \\
\hline Mean & 40.80 & 0.05 & 0.20 & 0.64 & 0.17 & 0.24 & 0.33 \\
\hline Max & 49.81 & 0.06 & 0.24 & 0.79 & 0.21 & 0.30 & 0.39 \\
\hline Min & 32.66 & 0.04 & 0.16 & 0.51 & 0.13 & 0.19 & 0.26 \\
\hline FB14 & 43.25 & 0.05 & 0.21 & 0.66 & 0.21 & 0.25 & 0.36 \\
\hline FB15 & 40.61 & 0.05 & 0.20 & 0.63 & 0.14 & 0.24 & 0.31 \\
\hline FB16 & 35.41 & 0.04 & 0.17 & 0.54 & 0.18 & 0.20 & 0.30 \\
\hline FB17 & 32.02 & 0.04 & 0.16 & 0.49 & 0.19 & 0.18 & 0.29 \\
\hline FB18 & 38.45 & 0.05 & 0.19 & 0.59 & 0.16 & 0.22 & 0.31 \\
\hline FB19 & 27.60 & 0.03 & 0.13 & 0.43 & 0.12 & 0.16 & 0.23 \\
\hline FB20 & 54.86 & 0.07 & 0.27 & 0.85 & 0.19 & 0.32 & 0.42 \\
\hline Mean & 38.47 & 0.05 & 0.19 & 0.60 & 0.17 & 0.22 & 0.32 \\
\hline Max & 54.10 & 0.07 & 0.27 & 0.85 & 0.21 & 0.32 & 0.42 \\
\hline Min & 27.27 & 0.03 & 0.13 & 0.43 & 0.12 & 0.16 & 0.23 \\
\hline $\begin{array}{c}\text { Global } \\
\text { Average* }\end{array}$ & 84 & $<1$ & $<1$ & $<1$ & $<1$ & $<1$ & $<1$ \\
\hline
\end{tabular}

- Global Average*: Ref, [10]

The activity concentrations of ${ }^{226} \mathrm{Ra},{ }^{232} \mathrm{Th},{ }^{40} \mathrm{~K}$ and the calculated radium equivalent $\left(\mathrm{Ra}_{\mathrm{eq}}\right)$ compared with the data reported by other countries. As shown in Table 3, The results also compared with the mean world radionuclide concentrations of ${ }^{226} \mathrm{Ra},{ }^{232} \mathrm{Th}$ and ${ }^{40} \mathrm{~K}$ which were $(35,30$ and 400 $\mathrm{Bq} / \mathrm{kg}$ ) respectively [10]. From the comparison in Table 3, we found that all the risk indicators in the present study are lower than the worldwide and the permissible limits. Compared to the comparative studies on clay bricks in Egypt, they were found to be largely convergent. These results eventually lead to the clay bricks used in the study safe for use in Egypt. 
Table (3): Comparison of activity concentrations and radium equivalents (Bq/kg) for all type bricks sample with different counters of the world

\begin{tabular}{cccccc}
\hline Country & ${ }^{226} \mathbf{R a}$ & ${ }^{232} \mathbf{T h}$ & ${ }^{40} \mathbf{K}$ & $\mathbf{R a}_{\text {eq }}$ & Reference \\
\hline Australia & 41 & 89 & 681 & 220 & {$[\mathbf{1 3}]$} \\
China & 41 & 52 & 717 & 171 & {$[\mathbf{2 6}]$} \\
Egypt & 20 & 14 & 204 & 56 & {$[9]$} \\
Finland & 78 & 62 & 962 & 241 & {$[\mathbf{2 5}]$} \\
Germany & 59 & 67 & 673 & 207 & {$[\mathbf{2 5}]$} \\
Greece & 49 & 24 & 670 & 135 & {$[\mathbf{2 2}]$} \\
Netherlands & 39 & 41 & 560 & 141 & {$[\mathbf{2 7}]$} \\
Norway & 104 & 62 & 1058 & 276 & {$[17]$} \\
Sweden & 96 & 127 & 962 & 352 & {$[\mathbf{2 5}]$} \\
Sri Lanka & 35 & 72 & 585 & 183 & {$[\mathbf{2 8}]$} \\
Kuwait & 6.6 & 6.6 & 332 & 41.6 & {$[\mathbf{2 9}]$} \\
Malaysia & 233 & 229 & 685 & 612 & {$[\mathbf{3 0}]$} \\
Bangladesh & 29 & 52 & 292 & 127 & {$[31]$} \\
India & $\mathrm{BDL}$ & 17.12 & 235.59 & 187 & {$[\mathbf{2 0}]$} \\
Pakistan & 45 & 61 & 692 & 187 & {$[\mathbf{3 2}]$} \\
Present Work & 35 & 30 & 213 & 94 & \\
Global Average* & $\mathbf{3 5}$ & $\mathbf{3 0}$ & $\mathbf{4 0 0}$ & $\mathbf{3 7 0}$ & {$[\mathbf{1 0}]$} \\
\hline
\end{tabular}

- Global Average*: Ref, [10]

\section{Conclusion}

The activity concentration of 226Ra, 232Th and $40 \mathrm{~K}$ measured in commonly used (different types of clay brick samples) for construction purpose in Egypt determined by high purity germanium detector. The measured values of the activity concentrations of 226Ra, 232Th and $40 \mathrm{~K}$ in (BC) brick samples found to be in the ranges of (33-46), (31-61) and (137-239) Bq/kg respectively.Gamma Spectroscopy System used in our study is the effective method for measuring the activity of radioisotopes. In this study, we able to measure the average values of the radioactivity concentration of $226 \mathrm{Ra}, 232 \mathrm{Th}$ and $40 \mathrm{~K}$ are for clay brick (CB) which were $(39,38$ and 199 $\mathrm{Bq} / \mathrm{kg}$ ), for making facade brick (MFB) which were $(33,26$ and $217 \mathrm{~Bq} / \mathrm{kg})$ and for fire brick (FB) which were $(33,22$ and $221 \mathrm{~Bq} / \mathrm{kg}$ ). Radium equivalent activity Raeq mean calculated of clay brick (CB), making the facade brick (MFB) and fire brick (FB) are 110, 88 and $83 \mathrm{~Bq} / \mathrm{kg}$. Radium equivalent activities for all type of bricks are satisfactorily lower than allowable level of 370 $\mathrm{Bq} / \mathrm{kg}$. Hazard indexes Hin and Hex are below unity and $\mathrm{I} \gamma$ and $\mathrm{I} \alpha$ are below the recommended values. Therefore, all clay brick samples used in the present study, which were manufactured from the raw material of the Nile River clay, are currently exempt from all restrictions on radioactivity, and this clay brick samples are safe for use in building construction.. This study showed that all the clay bricks commonly used in the construction of buildings in Egypt are safety.

\section{References}

1. Florou, H. and P. Kritidis,. Gamma radiation measurements and dose rate in the coastal areas of a volcanic Island, Aegean Sea, Greece. Radiation Protection Dosimetry ., 45, 1: 277 279 (1992) DIO:10.1093/rpd/45.1-4.277;

2. Florou, H., G.Trabidou and G.Nicolaou,. An assessment of the external radiological impact in areas of Greece with elevated natural radioactivity, 93: $\quad 74-\quad 83$ (2007). DOI:10.1016/j.jenvrad.2006.11.009; PMID 17257715;

3. Ahmed, N.K,. Measurement of Natural Radioactivity in Building Materials in Qena City, Upper Egypt. Journal of Environmental 


\begin{tabular}{|c|c|}
\hline Radioactivity, & 83: $\quad 91-99$ \\
\hline $\begin{array}{l}\text { DOI: } 10.1016 / j . j e \\
15935911 ;\end{array}$ & envrad.2005.03.002 \\
\hline
\end{tabular}

4. El-Taher, A. Gamma Spectroscopic Analysis and Associated Radiation Hazards of Building Materials Used in Egypt. Radiation Protection Dosimetry, 138: $166-173$ (2010). DOI: $10.3923 / \mathrm{jest} .2016 .238 .245$;

5. Mostafa, A.M.A. Natural radioactivity and radiological hazards in some building materials used in New Assiut city, Egypt. Conference: International Conference on New Horizons in Basic and Applied Science At: Hurghada Egypt, Volume: 1 (2013).

6. Mahmoud Uosif, MA.. Specific Activity of ${ }^{226} \mathrm{Ra},{ }^{232} \mathrm{Th}$ and ${ }^{40} \mathrm{~K}$ for Assessment of Radiation Hazards from Building Materials Commonly Used in Upper Egypt, SDU Journal of Science. 6 2: 120-126 (2011).

7. Al-Zahrani, J.H. Radioactivity Measurements and Radiation Dose assessments in Soil of Albaha Region Life science journal., 9, 3: 2391-2397 (2012).

8. Xinwei, L. Natural radioactivity in some building materials of Xi'an, China. Radiat Meas., 40:94-97 (2005). DOI: $\underline{10.1016 / j . r a d m e a s .2005 .01 .003}$

9. El-Tahawy, M.S., Higgy, R.H.,. Natural radioactivity in different types of bricks fabricated and used in Cario region. Appl. Radiat. Isot. 46 (12), 1401-1406 (1995). DOI: org/10.1016/0969-8043(95)00220-8

10. 10- United Nations Scientific Committee on Effects of Atomic Radiation (UNSCEAR) Report to the general assembly, vol I. Sources and effects of ionizing radiation. United Nations, New York (2000).

11. Khandaker, MU., PJ. Jojo and H.A. Kassim. Radiometric analysis of construction materials using HPGe gamma-ray spectrometry. Radiat Prot Dosim., 152: 33-37 (2012). DOI:10.1093/rpd/ncs145

12. Solak, S., S.Turhan and F.A. Ugur. Evaluation of potential exposure risks of natural radioactivity levels emitted from building materials used in Adana, Turkey. Indoor Built Environ, 23(4): 594-602 (2014). DOI: 10.1177/1420326X12448075

13. Beretka, J. and P.J.Mathew. Natural radioactivity of Australian building materials, industrial wastes and by product, Health Phys., 48: 87-95 (1985). DOI: $10.1097 / 00004032-$ 198501000-00007
14. Svoukis, E. and H.Tsertos. Indoor and outdoor in situ high-resolution gamma radiation measurements in urban areas of Cyprus. Radiat Prot Dosim. 123, 3:384-390 (2007).

15. Mehdizadeh, S. R. Faghihi and S.Sina. Natural radioactivity in building materials in Iran. NUKLEONIKA， 56, 4:363-368 (2011).

16. Krisiuk, E.M., Tarasov, S. I. and Shamov, V. P.,. A Study of Radioactivity in Building Materials. Research Institute of Radiation Hygeine Leningrad (1971).

17. Stranden, E. Some aspects on radioactivity of building materials, Physics Norwav., 8:167173 (1979).

18. Krieger, R. Radioactivity of Construction Materials. Betonwerk und FertigteilTechnik/Concrete Precasting Plant and Technology, 47, 468-446 (1981).

19. Keller, $G$ and H.Muth. Natural radiation exposure and medical radiology. In: Scherer, E., Streffer, Ch., Tolt, K.R.(Eds.), Radiation Exposure and Occupational Risks, SpringerVerlag, Berlin (1990).

20. Ravisankara, R, Vanasundaria K. and Chandrasekaranb A.. Measurement of Natural Radioactivity in Brick samples of Namakkal, Tamilnadu, India using Gamma-ray Spectrometry, Scholars Research Library Archives of Physics Research, 2, 2: 95-99 (2011).

DOI: org/10.1016/j.apradiso.2011.12.001

21. European Commission. Radiological protection principles concerning the natural radioactivity of building materials. Radiation protection 112. Directorate General Environment, Nuclear Safety and Civil Protection (Geneva: EC) (1999).

22. Brussels.Stoulos, S, M. Manolopoulo and C. Papastefanou. Assessment of natural radiation exposure and radon exhalation from building materials in Greece. J Environ Radioact, 69:225-240 (2003). DOI: org/10.1016/S0265931X(03)00081-X

23. Shadiah, S. Baz, Al-Ghamdi A.H. and Afaf Ahmed Fakeha. Natural radioactivity measurement and evaluation of radiological hazards in some environmental materials from Aswan area, Upper Egypt, Journal of American Science.11(3) (2015).

24. Alharbi1 W. R. and A. El-Taher,. Elemental Analysis and Natural Radioactivity Levels of Clay, by Gamma Ray Spectrometer and Instrumental Neutron Activation Analysis, Hindawi Publishing Corporation Science and 
Technology of Nuclear Installations Volume, 5 pages (2016). DOI: $10.1155 / 2016 / 8726260$

25. NEA-OECD. Nuclear Energy Agency. Exposure to radiation from natural radioactivity in building materaials. Report by NEA group of Experts, OECD, Paris (1979).

26. Pan, Yang Y and M.Guo. Natural radiation and radioactivity in China. Radiat. Prot Dosim, 7:235-238 (1984).

27. Ackers, J.G., J.F Den Boer and P. De Jong. Radioactivity and radon exhalation rates of building materials in the Netherlands, The Sci.Total Environ., 45: 151 (1985).

28. Hewamanna, R., C.S Sumithrarachchi and P. Mahawatte. Natural radioactivity and gamma dose from Sri Lankan clay bricks used in building construction, App. Rad.Isotopes., 54: 365 (2001). DOI: org/10.1016/S09698043(00)00107-X

29. Bou-Rabee, F and B. Bem. Natural radioactivity in building materials utilized in the State of Kuwait, J.Radioanal.Nucl.Chem., 213: 143 (1996)

30. Chong, C.S and G.U. Ahmad. Gamma activity of some building materials in West Malaysia, Health Physics., 43: 272 (1982).

31. Chowdhury IM., Alam MN and Ahmed AKS et al.. Concentration of radionuclides in building and ceramic materials of Bangladesh and evaluation of radiation hazard. J Radioanal Nucl Chem; 231: 117-122 (1998).

32. Tufail, M., Nasim-Akhtar and Sabiha-Javied. Natural radioactivity hazards of building bricks fabricated from saline soil of two districts of Pakistan, Journal of Radiological Protection., 27: $481 \quad$ (2007). $\quad$ DOI: $10.1088 / 0952-$ $\underline{4746 / 27 / 4 / 009}$ 